\title{
BALANCING THE PERSONALITY OF PROGRAMMER: SOFTWARE DEVELOPMENT TEAM COMPOSITION
}

\author{
Abdul Rehman Gilal ${ }^{1}$, Jafreezal Jaafar ${ }^{2}$, Mazni Omar ${ }^{3}$, Shuib Basri ${ }^{4}$, Izzatdin Abdul Aziz ${ }^{5}$ \\ 1,2,4,5 Department of Computer and Information Sciences, Universiti Teknologi PETRONAS, Malaysia \\ ${ }^{1}$ Department of Computer Science, Sukkur Institute of Business Administration, Pakistan \\ ${ }^{3}$ School of Computing, Universiti Utara Malaysia
}

Email: a-rehman@iba-suk.edu.pk ${ }^{1}$,jafreez@petronas.com.my²,mazni@uum.edu.my ${ }^{3}$, shuib_basri@petronas.com.my ${ }^{4}$,izzatdin@petronas.com.my ${ }^{5}$

\begin{abstract}
The production of software and their effectiveness have become the prerequisite for the development of various sectors of the world. Persistent demand for the software, feasible and effective in nature to address the clients' demand have levitated the interest amongst researchers to determine the factors that idealize the software development team since an adept and compatible team members, in terms of personality, are likely to ensure the success of software. In this regard, personality clashes have been attributed as the prominent factors of all to the failure of the software. Although copious research studies have been carried out in the past to suggest ideal and compatible personalities for making an ideal software development team, it is regret to add that the findings of these studies have rather enhanced the gravity of the problem for giving different suggestions for composing an ideal team for software development. To lessen such confusion, this study aims to propose solution for personality-based team composition by executing the different ranges of the programmer's role based on Myer Brig Type Indicator (MBTI) pairs. This method supposedly allows the researchers to reach the suitable conclusion by thorough investigation of all traits of personality for programmer role. In order to attain the best solution, student population was involved to develop the software projects in teams. The experiments were divided into two segments: defining balancing benchmark and validating the benchmark. In outcomes, this study proposed different ranges of personality traits based on gender classification for software programmers.
\end{abstract}

Keywords: Human aspects, MBTI, Personality types, Programmer, Gender, Software development, Team composition, Team balancing

\subsection{INTRODUCTION}

Development team plays key and pivotal role to ensure the success of software development projects. Each member of the software development project renders his/her best services and paves the way for another member of the project to carry out the task with an ease. Therefore, personality clashes among team members are likely to bring failure to the software projects [1]. This view can also be supported in the light of previous report [2] where personal clashes amongst team members caused $42 \%$ software failure, while $52 \%$ software were challenged in terms of their effectiveness to address the demands of the clients.

Each team member possesses two distinctive skills, namely hard (technical) and soft (social) skills. However, it is deplorable to say that software development team only prioritizes the hard skills of the team members and the soft skills of the team members are not taken into consideration. Consequently, this ignorance rewards software projects with darker perspectives [3], [4] because it is soft skills that determines an ideal human who can also exhibit required hard or technical skills for successful software team development. In the same vein, Martínez et al. [5] asserted that although it is undeniable fact that technical aspects cannot be overlooked to yield the desired performance of software development, yet the soft skills cannot be put apart that sets the nature of the personality types of the individual that is also correlated with the technical skills of team members.

The success of the software development can be ensured when the both technical and social skills of individuals are taken into account [5], [6]. Simply, personality types of team members matter to the great extent in 
determining the quality of software [7], [8]. For instance, the findings of the study by Gulla [6] suggested ineffective team composition as one of the seven leading factors causing IT projects to face terrible failure. Hence, it is advisable to include those team members who are flexible and adaptable with other team members, especially when their personality types match with one another in software team composition [9]. Although numerous studies have been conducted [10], [35] to address this problem of making an effective team composition, this issue seems to be still unaddressed as there still lies confusions among software management as what kind of personality type should be included and excluded for team composition.

The past research studies on team composition have also created some ambiguities for software development management for giving different suggestions for an ideal team composition. For example, the research study by Gorla and Lam [10] strongly recommended the inclusion of an extrovert (E) personality trait as the key for making programmer effective in teams. On the contrary, Capretz and Ahmed [3] recommended an introvert (I) personality trait for effective programmers. Moreover, previous studies have also highlighted particular types of personalities for roles rather than adjusting the other traits within teams. Such findings have rather aggravated the gravity of the problem amongst software developers. To address this problem, we proposed a solution for personality-based team composition. This study has introduced different ranges of MBTI pairs for programmer role. It implies that the solution allows to include all traits of MBTI with different ranges to avail the maximum benefits of all types of personality for programmer role.

\subsection{RELATED WORK}

Personality refers to the internal psychological patterns such as feelings and thoughts which carve the behavior of a person. Simply, personality traits are formed from within forces. Numerous studies have been carried out in the past applying many theoretical frameworks widely used in the domain of psychology to better understand personality. These theoretical frameworks include [11]: (1) dispositional, (2) biological, (3) psychoanalytic, (4) neoanalytic, (5) learning, (6) phenomenological and (7) cognitive self-regulation. Cruz et al. [11] also mentioned that the past research studies have not only used dispositional perspective abundantly so as to determine the personality traits and types in organizational psychology but it has also been used commonly in the field of software engineering to determine the most suitable personalities to form an ideal team for software development. Similarly, the present review explores the key importance of personality perspective which is handy for software development.

Dispositional perspective of psychology that sheds light on trait and type approach depicts the fact that the personality deals with internal stable qualities that vary from individual to individual and it also influences behavior. American Psychiatric Association defined 'trait' as "enduring patterns of perceiving, relating to, and thinking about the environment and oneself that are exhibited in a wide range of social and personal contexts." Thus, the personalities of the people are determined by their personality patterns classified by psychological differences. Moreover, both personality type and trait can be distinguished as the former demonstrates different levels and degrees while types are discrete as they cannot be distinguished by levels and degrees [11].

There are some key theories pertinent to personalities that have been profusely implemented in psychological and computing research studies [12]. The most prominent among them are: Keirsey Temperament Sorter [13], Five- Factor Model (FFM), which is also known as Big Five [14], and Myers-Briggs Type Indicator (MBTI) [15]. The distinctive point amongst these three personality theories is the way of describing the types of personality. Keirsey Temperament Sorter accentuates on the long term behavior of the individuals [16]. Meanwhile, FFM encompasses five distinctive personality traits such as: conscientiousness, agreeableness, openness to experience, extraversion, and agreeableness. On the contrary, MBTI mainly probes into what people think. According to Furham [17], both MBTI and Big Five personality tests are lucrative when a researcher aims to examine behavioral and cognitive sides of individuals by correlating both scales. However, there are many proponents of MBTI in the domain of software engineering as this theory has been widely used in the past research studies [1], [4], [7], [18]-[24]. Thus, keeping in view the wide acceptance of MBTI in terms of its effectiveness, the current study has used this theory.

MBTI primarily focuses on four pairs of personalities which can be further classified into sixteen types. The four pairs are namely, Extroversion-Introversion (I-E), Sensing-Intuitive (S-N), Thinking-Feeling (T-F) and Judging-Perceiving (J-P) [4] [22], respectively. These four dimensions also beget sixteen possible combinations of personality types as shown in Table 1 . 
Table 1: The 16 MBTI Personality Types

\begin{tabular}{l|l|l|l} 
ISTJ (1) & ISFJ (2) & INFJ (3) & INTJ (4) \\
\hline ISTP (5) & ISFP (6) & INFP (7) & INTP (8) \\
\hline ESTP (9) & ESFP (10) & ENFP (11) & ENTP (12) \\
\hline ESTJ (13) & ESFJ (14) & ENFJ (15) & ENTJ (16)
\end{tabular}

Based on the performance and score, a person can be attributed to one of the sixteen personality types cited in Table 1. For instance, a person who scores higher on Introversion (I) than Extroversion (E), Sensing (S) than Intuition $(\mathrm{N})$; Judging $(\mathrm{J})$ than Perceiving $(\mathrm{P})$; and Thinking $(\mathrm{T})$ than Feeling $(\mathrm{F})$, would be categorized as an ISTJ.

\subsection{Gender}

Gender has also been raised as the crucial factor in the two leading theories that have been widely used in the past research studies on gender and IT: social construction and essentialism [25]. Essentialism refers to the diverse nurture of males and females that is unified and fixed in the nature (p. 9) [26]. The distinctive differences between males and females have led researchers to develop the assumption that they exhibit different personality traits and types because they are determined by the biological variations [25]. Similar differences across the gender has also been determined in the past research studies on IT. Thus, these studies in the domain of IT have concluded that behavioral differences between men and women are fixed, inherited and very much bio-psychological in nature. Trauth [25] further asserted that study on gender and IT by applying the philosophy of essentialism refers gender as the fixed variable that is influenced by positivist epistemology. The thorough analysis of such viewpoints establishes the fact that merely exploring the psychological perspectives across gender in the field of IT rather than narrowing down characteristics of individual gender. Meanwhile, researchers ought to bring into account the context while observing the psychological explanations of observations across gender [27].

\subsection{Software Programmer and Personality}

The past research studies empirically proved the relationship between MBTI and computer programming [28]. In one of the studies, Capretz [29] conducted experiments on Brazilian software engineering students to propose a personality profile for software developers. In his study, a total of 68 students participated and majority of them were males. Moreover, the author concluded that ISFP, INTP and ESTP personality types were significantly overrepresented among Brazilian software engineering students. On the other hand, ENTP, ESTJ and ENTJ personality types were significantly underrepresented among them. Having the same view, Martínez [30] proposed a methodology for assigning roles to software developers. They divided the research experiments into two cases: training and testing with 12 and 16 participants, respectively. The outcomes of the study revealed that ISTP personality type is best fitted for programmer role. Additionally, Capretz and Ahmed [3] also highlighted the same objective in which software development tasks were contrasted with personality types. In their study, personality types were mapped to job requirements collected from newspaper, magazines and online forums. At the end, authors recommended ISTJ and ISTP personality types for programmer role.

\subsection{METHODOLOGY}

The experiments of this study were conducted on the third year students of software engineering class from Universiti Utara Malaysia. The software engineering class was chosen based on the "20-year age" benchmark for students' selection. This is due to the fact that researchers in psychology domain claimed that personality type is an inheritance of the person. It does not change by the time, but it only paces to betterment in the same type of personality [32][33]. Past researchers also shown that person with age between 20-50 years old has stable and consistent personality types [32], which is the case of age amongst participants in this study. In the same vein Boyce et al. [34] stated that many experts from psychology field have shown their consent that personality does not change but people start dealing in the better way. Therefore, the academic participants who are at least 20 years old were considered in this study. Participants in teams comprise minimum of four or maximum of five members were required to develop a software project. Overall, 28 teams were formed. Specifically, 21 teams consisting 4 members and 7 teams consisting 5 members were formed. Each team comprised of one leader and the rest are programmers. Therefore, a total of 119 students (i.e., 28 leaders and 91 
programmers) participated in the experiments. The duration of the project was 16 weeks. The teams were asked to use extreme programming ("XP") method. The requirements of the project were same for all teams. However, the participants were given free hand to compose teams based on their understanding. The free hand team composing step was applied to select the best fit teams based on the team members' choice. Figure 1 represents the connections between variables of the study.

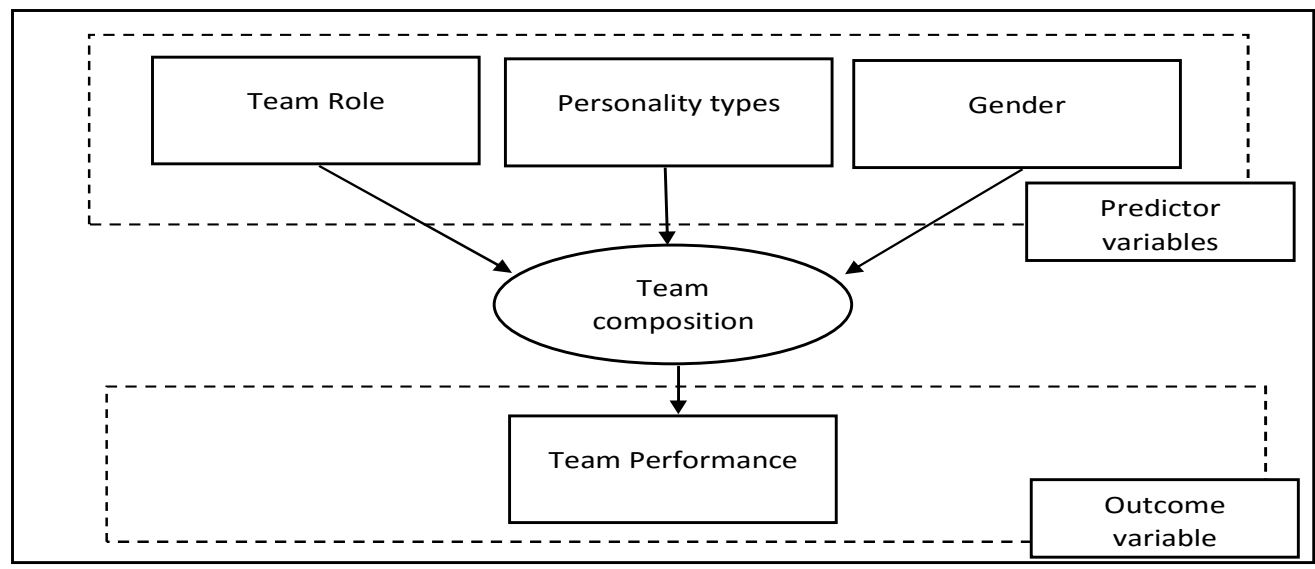

Fig. 1: Framework of the study

After the deadlines, the projects were collected from teams and then submitted to a requirement engineer for evaluation based on the given requirements. Then, the requirement engineer classified 12 teams as effective teams out of total 28 teams, as they were able to achieve $80 \%$ or above based on the requirements. It is worth mentioning here that $80 \%$ benchmark was chosen for quality development because it is marked as grade " $\mathrm{A}$ " in the university. Meanwhile, based on the evaluation of the requirement engineer, the remaining 16 teams could not meet the quality requirements.

The main objective of the study is to construct an ideal and balanced team for software development based on personality. According to Gilal et al. [1], programmer role requires different type of personalities for male and female. Therefore, variable gender was also kept to classify the personality type of programmer based on gender. Additionally, the MBTI was used to measure the personality type of programmer. In order to cop the myriad results from the dataset, the data analysis of the experiments were segregated based on the obtained quality marks of teams. Specifically, the teams which obtained $80 \%$ or above were selected as the "effective teams" while the teams which obtained below the benchmark (i.e., $80 \%$ ) were considered as "ineffective teams". Moreover, the experiments were divided into two segments: defining balancing benchmark and validating the benchmark. The first segment was conducted from effective teams by classifying gender. Meanwhile, the second segment was used to validate the claimed benchmarks from the ineffective teams. It was performed to examine the reasons or gaps between effective and ineffective teams.

\subsection{RESULTS AND DISCUSSION OF FIRST SEGMENT}

As mentioned earlier, gender was kept as classification variable for personality balancing experiments. Therefore, programmers were grouped based on gender and then a personality trait counter was applied to study the overall appearance of traits of programmer in teams. Table 2 presents the overall programmer appearance in effective teams.

All effective teams were classified based on the gender of programmers to investigate the difference between the male and female programmers' trait behavior. Prior to analyzing the collected data, it was appropriate to determine whether (or not) there was any statistical significant difference between male and female programmers. Therefore, two-sample independent $t$-test was applied over obtained values of personality traits for male and female genders. The finding of the test revealed that there was a statistical significant difference between males and females at $p=0.04$. It is significant as the sample independent $t$-test is always significant at $p<0.05$. All traits of MBTI were placed face-to-face to find the exact difference point in male and female programmers. It was clearly visible that male programmers require different amount of ratio as compared to female programmers in personality-based composition. Figure 2 shows the trait-to-trait comparison of male and female programmers. 
Table 2: Programmer appearance in effective teams

\begin{tabular}{|c|c|c|c|c|c|c|c|c|c|c|c|c|c|c|c|c|}
\hline \multirow{2}{*}{ Team ID } & \multicolumn{8}{|c|}{ Male } & \multicolumn{8}{|c|}{ Female } \\
\hline & I & $\mathbf{E}$ & $\mathbf{S}$ & $\mathbf{N}$ & $\mathbf{T}$ & $\mathbf{F}$ & $\mathbf{J}$ & $\mathbf{P}$ & I & $\mathbf{E}$ & $\mathbf{S}$ & $\mathbf{N}$ & $\mathbf{T}$ & $\mathbf{F}$ & $\mathbf{J}$ & $\mathbf{P}$ \\
\hline T3 & 0 & 0 & 0 & 0 & 0 & 0 & 0 & 0 & 0 & 3 & 1 & 2 & 1 & 2 & 3 & 0 \\
\hline T5 & 0 & 3 & 3 & 0 & 2 & 1 & 3 & 0 & 0 & 0 & 0 & 0 & 0 & 0 & 0 & 0 \\
\hline T6 & 0 & 0 & 0 & 0 & 0 & 0 & 0 & 0 & 2 & 2 & 3 & 1 & 2 & 2 & 4 & 0 \\
\hline $\mathrm{T} 7$ & 0 & 4 & 0 & 4 & 3 & 1 & 4 & 0 & 0 & 0 & 0 & 0 & 0 & 0 & 0 & 0 \\
\hline T11 & 0 & 1 & 1 & 0 & 1 & 0 & 0 & 1 & 0 & 2 & 2 & 0 & 1 & 1 & 2 & 0 \\
\hline T14 & 1 & 2 & 0 & 3 & 2 & 1 & 3 & 0 & 0 & 0 & 0 & 0 & 0 & 0 & 0 & 0 \\
\hline $\mathrm{T} 15$ & 0 & 0 & 0 & 0 & 0 & 0 & 0 & 0 & 1 & 2 & 1 & 2 & 3 & 0 & 3 & 0 \\
\hline $\mathrm{T} 17$ & 1 & 0 & 0 & 1 & 1 & 0 & 1 & 0 & 2 & 1 & 1 & 2 & 0 & 3 & 3 & 0 \\
\hline T18 & 1 & 2 & 1 & 2 & 2 & 1 & 3 & 0 & 0 & 0 & 0 & 0 & 0 & 0 & 0 & 0 \\
\hline $\mathrm{T} 20$ & 1 & 0 & 1 & 0 & 1 & 0 & 1 & 0 & 1 & 1 & 1 & 1 & 0 & 2 & 0 & 2 \\
\hline $\mathrm{T} 22$ & 0 & 0 & 0 & 0 & 0 & 0 & 0 & 0 & 3 & 0 & 2 & 1 & 2 & 1 & 2 & 1 \\
\hline $\mathrm{T} 23$ & 0 & 1 & 1 & 0 & 0 & 1 & 1 & 0 & 1 & 1 & 2 & 0 & 1 & 1 & 2 & 0 \\
\hline Total & 4 & 13 & 7 & 10 & 12 & 5 & 16 & 1 & 10 & 12 & 13 & 9 & 10 & 12 & 19 & 3 \\
\hline
\end{tabular}

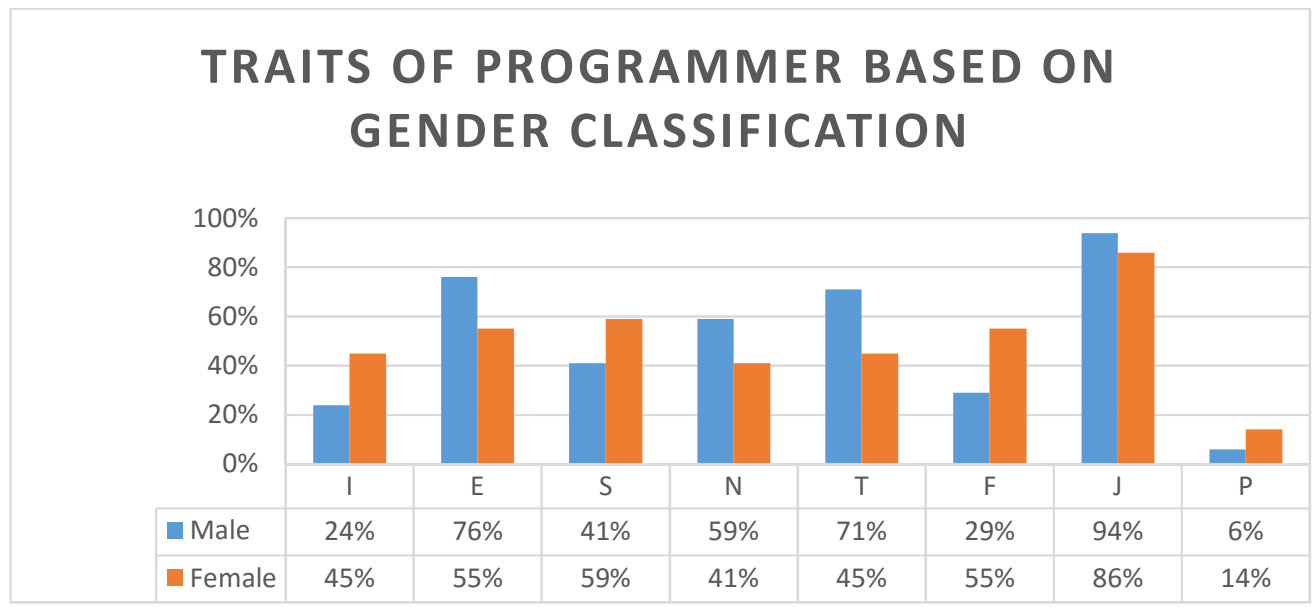

Fig. 2: Programmers' traits based on gender classification

Based on the results, a few claims can be inferred. The results in Fig. 2 suggested that I trait is always less than E trait in effective teams for both genders. For instance, male gender's I trait was $24 \%$ while E trait was $76 \%$. In the same vein, female programmer's ratio also showed I trait of $45 \%$ and $\mathrm{E}$ trait of $55 \%$. Moreover, the last pair of MBTI (i.e., JP) had also showed the similarity in choice for both male and female participants. Specifically, both male and female programmers have higher $\mathrm{J}$ trait than $\mathrm{P}$ trait. Nonetheless, the $\mathrm{SN}$ and TF pairs showed extremely opposite trend in male and female programmers. As shown in Fig. 2, it is obvious that the effective teams held about $59 \%$ male programmer with $\mathrm{N}$ trait and $41 \%$ with $\mathrm{S}$ trait. However, female programmer showed totally opposite trend in effective teams (i.e., $\mathrm{S}=59 \%$ and $\mathrm{N}=41 \%$ ). It implies that female programmers tend to focus on the present demands of development ( $\mathrm{S}$ trait) while collecting information. Meanwhile, male programmers focus more on the future image of development during the information collection class. Moreover, the TF pair of MBTI also exhibited opposite trend in both genders. For example, it is stated in [31] that females are person-centered and more emotional as compared to male while they are making decision. On the other hand, males focus more on the causes and effects. Therefore, the results also highlighted that male programmers 
showed $\mathrm{T}$ trait of $71 \%$ and $\mathrm{F}$ trait of only $29 \%$. Meanwhile, female programmers have shown their effectiveness in teams with $55 \%$ in $\mathrm{F}$ trait and $45 \%$ in $\mathrm{T}$ trait.

\subsection{CLAIMING THE BENCHMARK}

It was not sufficient yet to choose any benchmark to compose a balanced team with both male and female programmers. Hence, the next step was taken to investigate the internal difference between pairs of MBTI (or distance between traits). This claim had no objection that both genders are demanding different traits for programmer role [1]. Therefore, results were further highlighted with pair-wise differences in both genders. Table 3 shows the distance of traits within the pairs.

Table 3: Distance of traits among MBTI pairs

\begin{tabular}{|c|c|c|c|c|}
\hline Gender & IE & SN & TF & JP \\
\hline Male & $52 \%$ & $18 \%$ & $42 \%$ & $88 \%$ \\
\hline Female & $10 \%$ & $18 \%$ & $10 \%$ & $72 \%$ \\
\hline
\end{tabular}

These results were obtained from Fig. 2 by taking the absolute value of the difference between the pairs (i.e., subtracting the pairs' values with each other). Basically, absolute function converts the negative numbers into positive numbers. For instance:

$$
\text { Absolute }(I-E)=>\text { Absolute }(24-76)=>\text { Absolute }(-52)=>52
$$

Since the first segment of the study had already mentioned the significant traits for male and female programmer, these results were considered as the benchmark for the personality-based team balancing. For instance, SN and JP pairs had almost equal distance based on genders. However, male programmers require opposite traits as compared to female programmers. Meanwhile, male programmers in IE and TF demand high distance between I and E or T and F. On the other hand, short distance (i.e., only 10\%) was required in IE and TF pairs for female programmers.

\subsection{VALIDATING THE BENCHMARK}

The initial benchmarks were established from the first segment of the study but the validation had yet to be obtained. Therefore, as mentioned in the methodology section, ineffective teams were explored to investigate the reasons of failure by focusing on personality traits balancing. Recall that, 16 teams were considered as ineffective teams. The validation process was applied on these 16 teams by applying a 2 -fold approach. It means that these teams were randomly divided into two folds of 8-8 teams to find out the optimum results. A significant difference of $p=0.008$ was obtained using $t$-test. The results were more carefully investigated to avail the reasons of differences. Table 4 presents the basic view of the folds based on personality traits construction.

The ineffective teams were thoroughly compared with effective teams to find out the gap. For instance, the male programmers in effective teams had set about $24 \%$ for I trait and $76 \%$ for E trait. It showed that there was a difference of $52 \%$ between $\mathrm{E}$ trait and I trait male programmers. The result was further validated by comparing the results with ineffective male programmers, who were from the $1^{\text {st }}$ and $2^{\text {nd }}$ folds. I trait male programmers exhibited about $44 \%$ in $1^{\text {st }}$ fold and $42 \%$ in $2^{\text {nd }}$ fold, respectively within the ineffective teams. Besides, the percentage of $\mathrm{E}$ trait male programmers slopped down to $60 \%$ and hence the team was considered as ineffective. In the same vein, $S$ trait showed $22 \%$ in $1^{\text {st }}$ fold and $75 \%$ in $2^{\text {nd }}$ fold but effective male programmers showed $41 \%$. It can be inferred that male programmers with $\mathrm{S}$ trait may be effective if they are $41 \%$ or greater than $22 \%$ and less than $75 \%$ in team. Similarly, $N$ trait appeared effective at $59 \%$ for male programmers in a team. The TF pair of effective teams was compared with ineffective teams. Specifically, $56 \%$ and $33 \%$ were achieved from both folds respectively while the effective teams achieved $71 \%$ in $\mathrm{T}$ trait. Hence, we can say that $\mathrm{T}$ trait male programmers must have at least $56 \%$ appearance in a team for better results. 
Table 4: Construction of two-fold ineffective teams

\begin{tabular}{|c|c|c|c|c|c|c|}
\hline \multirow{3}{*}{ Traits } & \multirow{2}{*}{\multicolumn{2}{|c|}{ Effective }} & \multicolumn{4}{|c|}{ Ineffective } \\
\hline & & & \multicolumn{2}{|c|}{$1^{\text {st }}$-fold } & \multicolumn{2}{|c|}{$2^{\text {nd }}$-fold } \\
\hline & Male & Female & Male & Female & Male & Female \\
\hline I & $24 \%$ & $45 \%$ & $44 \%$ & $33 \%$ & $42 \%$ & $37 \%$ \\
\hline $\mathbf{E}$ & $76 \%$ & $55 \%$ & $56 \%$ & $67 \%$ & $58 \%$ & $63 \%$ \\
\hline $\mathbf{S}$ & $41 \%$ & $59 \%$ & $22 \%$ & $27 \%$ & $75 \%$ & $75 \%$ \\
\hline $\mathbf{N}$ & $59 \%$ & $41 \%$ & $78 \%$ & $73 \%$ & $25 \%$ & $25 \%$ \\
\hline $\mathbf{T}$ & $71 \%$ & $45 \%$ & $56 \%$ & $47 \%$ & $33 \%$ & $50 \%$ \\
\hline $\mathbf{F}$ & $29 \%$ & $55 \%$ & $44 \%$ & $53 \%$ & $67 \%$ & $50 \%$ \\
\hline $\mathbf{J}$ & $94 \%$ & $86 \%$ & $67 \%$ & $100 \%$ & $67 \%$ & $75 \%$ \\
\hline $\mathbf{P}$ & $6 \%$ & $14 \%$ & $33 \%$ & $0 \%$ & $33 \%$ & $25 \%$ \\
\hline
\end{tabular}

On the other hand, female programmers' benchmarks were also measured with the same way to ensure the effective results. Firstly, it was observed that when there was a higher difference between the traits of IE pairs for female programmer, the team tends to be weak and ineffective. As mentioned in Table 3, IE pair for female programmers showed $10 \%$ distance between traits for effective teams. It was then proved after looking at $1^{\text {st }}$ and $2^{\text {nd }}$ folds which obtained $34 \%$ and $26 \%$ distance within the traits of IE pair, respectively. Secondly, in the SN pair, S trait appeared 59\% from effective female programmers. Whilst, for the SN pair, 27\% in 1st-fold and $75 \%$ in 2 nd-fold were found from ineffective teams. It is, therefore, the distance between traits within the pairs was important to measure.

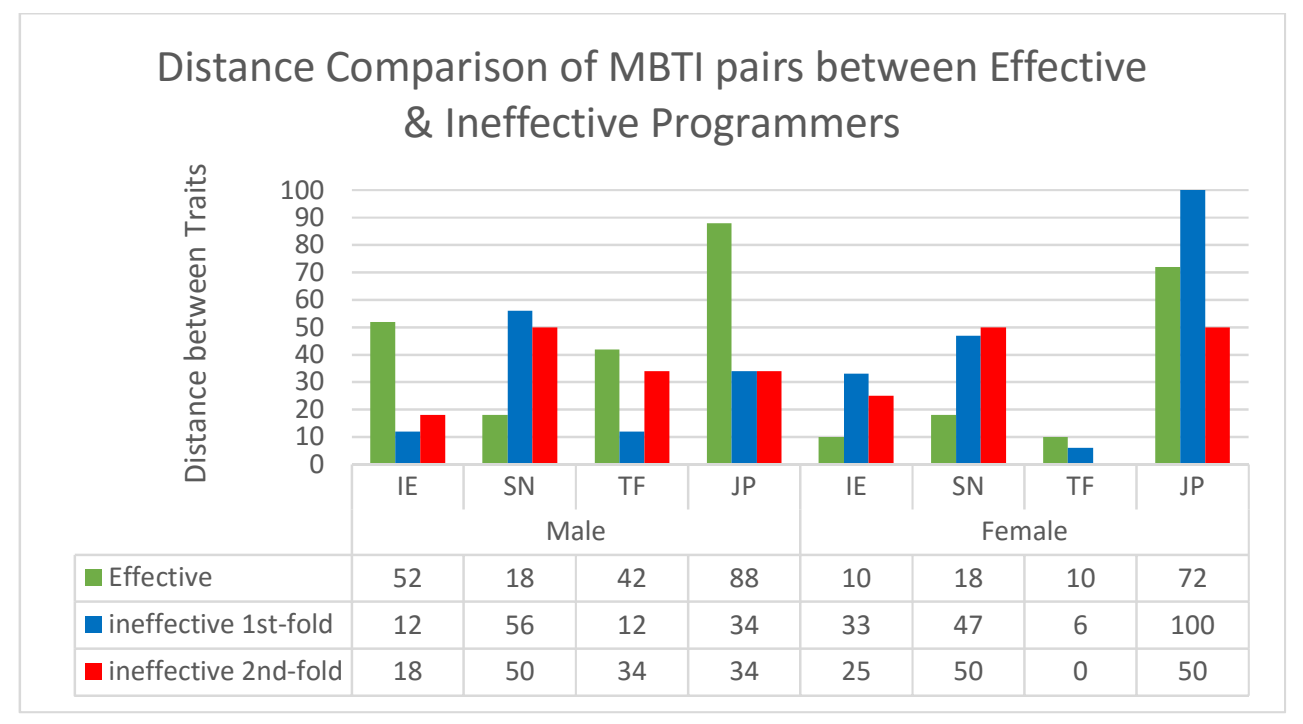

Fig. 3: Comparison of distance between MBTI pairs for effective and ineffective programmers

Keeping in view, in male programmers, the difference between IE pair was $52 \%$ in effective teams and $12 \%$ and $18 \%$ from 1 st fold and $2^{\text {nd }}$ folds of ineffective teams, respectively. Based on these results, it is obvious that less difference between traits have caused the ineffectiveness within the teams. In the same vein, SN pair from effective teams showed low difference between traits for male and female programmers but high differences 
were achieved between traits from both folds of ineffective teams (i.e., see SN pair in Fig. 3). The TF pair of effective male programmer required about $42 \%$ difference for balanced composition and up to $34 \%$ difference was found in $2^{\text {nd }}$ fold of ineffective teams. Similarly, effective female programmer's pair of IE was found effective with low difference of $10 \%$. However, $33 \%$ from $1^{\text {st }}$ fold and $25 \%$ from $2^{\text {nd }}$ fold were observed. Lastly, $\mathrm{TF}$ pair of female programmer required $10 \%$ difference for effective balancing teams. During, difference findings from folds, it was observed that lower than $10 \%$ also does not ensure the effectiveness. Hence, for only $\mathrm{TF}$ pair of female programmer, this claim can be made that $10 \%$ difference is minimal for effective team balancing.

\subsection{CONCLUSION}

It is not easy to conclude that particular personality trait is suitable for programmer (or any role) in the domain of psychology. Moreover, it is not easy to obtain the demanded personality types for any role of software development. Each trait of personality has its own importance in the field of psychology. Therefore, this research has set a few ranges of personality traits within the pairs of MBTI for programmer role to construct a balanced software development team. Table 5 consists the summary of all traits against the desire ranges.

Table 5: Summary of Team Balancing Ranges

\begin{tabular}{|c|c|c|c|c|}
\hline Traits & Male & Difference Range & Female & Difference Range \\
\hline I & $\mathrm{L}$ & \multirow{2}{*}{$52 \%$ (must be $>18 \%$ ) } & $\mathrm{L}$ & \multirow{2}{*}{$10 \%$ (must be $<25 \%$ ) } \\
\hline $\mathbf{E}$ & $\mathrm{H}$ & & $\mathrm{H}$ & \\
\hline $\mathbf{S}$ & $\mathrm{L}$ & \multirow{2}{*}{$18 \%$ (must be $<50 \%$ ) } & $\mathrm{H}$ & \multirow{2}{*}{$18 \%$ (must be $<47 \%$ ) } \\
\hline $\mathbf{N}$ & $\mathrm{H}$ & & $\mathrm{L}$ & \\
\hline $\mathbf{T}$ & $\mathrm{H}$ & \multirow{2}{*}{$42 \%$ (must be $>34 \%$ ) } & $\mathrm{L}$ & \multirow{2}{*}{$10 \%$ (must be $>=10 \%$ ) } \\
\hline $\mathbf{F}$ & $\mathrm{L}$ & & $\mathrm{H}$ & \\
\hline $\mathbf{J}$ & $\mathrm{H}$ & \multirow{2}{*}{$88 \%$ (must be $>34 \%$ ) } & $\mathrm{H}$ & \multirow{2}{*}{$72 \%$ (must be $>50 \%$ ) } \\
\hline $\mathbf{P}$ & $\mathbf{L}$ & & $\mathbf{L}$ & \\
\hline
\end{tabular}

The first part of this research extracted certain ranges of MBTI pairs. In each pair, one trait appeared higher than the others. Therefore, the term L denotes that trait must be lower than the other trait within the same pair. For instance, I trait is L (Lower) in male and female programmers as compared to E trait. It implies that I trait must be less than $\mathrm{E}$ trait with at least $18 \%$ of difference in male programmer's personality.

Keeping in view, different ranges were obtained for the male and female programmers. It was also highlighted that differences between the traits of MBTI pairs could also be considered as of the reasons of poor performance. Specifically, the IE pair demands at least $18 \%$ of difference between I and E traits for male programmers. On the other hand, the same pair for female programmers requires less than $25 \%$ difference. Almost similar amount of difference range is observed within the SN pair but male programmers require $\mathrm{S}$ trait $\mathrm{L}$ (lower) and $\mathrm{N}$ trait $\mathrm{H}$ (higher) with $18 \%$ difference. Meanwhile, female programmers require exact opposite trend (i.e., $\mathrm{S}$ trait $\mathrm{H}$ (higher) and $\mathrm{N}$ trait $\mathrm{L}$ (lower)). The third pair, TF, claims at least $34 \%$ difference between traits for male programmer and at least $10 \%$ difference for female programmers. However, male programmers require $\mathrm{T}$ trait higher than $\mathrm{F}$ trait and female programmers demand exact opposite trend.

\subsection{LIMITATIONS AND FUTURE WORKS}

The intentions of this research were to start a new area of team balancing in the field of software development team composition based on personality types. The findings obtained from this research cannot be generalized with industries and other countries because the data was collected from universities in Malaysia only. Therefore, in order to minimize the threats to validity, we shall conduct experiments in industrial environment settings as well as in other countries. Different methodologies and team roles of software development can also be examined within the domain of personality-based team compositions. 


\section{REFERENCES}

[1] A. R. Gilal, J. Jaafar, M. Omar, and M. Z. Tunio, "Impact of Personality and Gender Diversity on Software Development Teams' Performance," in International Conference on Computer, Communication, and Control Technology (I4CT 2014), 2014, no. 2014 IEEE 2014, pp. 261-265.

[2] I. The Standish Group Internatinal, "BIG BANG BOOM,” pp. 1-12, 2014. Accessed from https://www.standishgroup.com/sample_research_files/BigBangBoom.pdf, 2014.

[3] L. F. Capretz and F. Ahmed, "Making sense of software development and personality types," IT Prof., vol. 12, no. 1, pp. 6-13, 2010.

[4] A. R. Gilal, M. Omar, and K. I. Sharif, “,” J. Inf. Commun. Technol, no. JICT Vol. 13, 2014, pp. 1-20, 2014.

[5] L. G. Martínez, A. Rodríguez-Díaz, G. Licea, and J. R. Castro, "Big five patterns for software engineering roles using an ANFIS learning approach with RAMSET," in Advances in Soft Computing, Springer, 2010, pp. 428-439.

[6] J. Gulla, "Seven Reasons Why Information Technology Projects Fail,” IBM Corp. August, vol. 11, 2011.

[7] R. G. Raj and S. Abdul-Kareem. "A Pattern Based Approach for The Derivation Of Base Forms Of Verbs From Participles And Tenses For Flexible NLP," Malaysian Journal of Computer Science, Vol. 24(2): Jun 2011. pp 63-72.

[8] S. T. Acuña, M. Gómez, and N. Juristo, "How do personality, team processes and task characteristics relate to job satisfaction and software quality?," Inf. Softw. Technol., vol. 51, no. 3, pp. 627-639, 2009.

[9] R. Colomo-Palacios, E. Tovar-Caro, Á. García-Crespo, and J. M. Gómez-Berbís, "Identifying technical competences of IT professionals: The case of software engineers," Int. J. Hum. Cap. Inf. Technol. Prof., vol. 1, no. 1, pp. 31-43, 2010.

[10] N. Gorla and Y. W. Lam, "Who should work with whom?: building effective software project teams," Commun. ACM, vol. 47, no. 6, pp. 79-82, 2004.

[11] S. Cruz, F. Q. B. da Silva, and L. F. Capretz, "Forty years of research on personality in software engineering: A mapping study," Comput. Human Behav., vol. 46, pp. 94-113, 2015.

[12] M. Omar, N. Katuk, S. L. S. Abdullah, N. L. Hashim, and R. Romli, “Assessing Personality Types Preferences Amongst Software Developers: A Case Of Malaysia," ARPN J. Eng. Appl. Sci., vol. VOL. 10, N, no. FEBRUARY 2015, pp. 1499-1504, 2015.

[13] M. Bates and D. Keirsey, "Please Understand Me: Character and Temperament Types," Del Mar Prometh. Nemesis B. Co, 1984.

[14] R. R. McCrae and O. P. John, “An introduction to the five-factor model and its applications," J. Pers., vol. 60, no. 2, pp. 175-215, 1992.

[15] I. B. Myers, M. H. McCaulley, N. L. Quenk, and A. L. Hammer, MBTI manual: A guide to the development and use of the Myers-Briggs Type Indicator, vol. 3. Consulting Psychologists Press Palo Alto, CA, 1998.

[16] L. J. Francis, C. L. Craig, and M. Robbins, “The relationship between the Keirsey Temperament Sorter and the short-form revised Eysenck Personality Questionnaire," J. Individ. Differ., vol. 29, no. 2, pp. 116-120, 2008. 
[17] A. Furnham, "The big five versus the big four: the relationship between the Myers-Briggs Type Indicator (MBTI) and NEO-PI five factor model of personality," Pers. Individ. Dif., vol. 21, no. 2, pp. 303-307, 1996.

[18] J. H. Bradley and F. J. Hebert, "The effect of personality type on team performance," J. Manag. Dev., vol. 16 , no. 5 , pp. 337-353, 1997.

[19] J. S. Karn and A. J. Cowling, "Using ethnographic methods to carry out human factors research in software engineering," Behav. Res. Methods, vol. 38, no. 3, pp. 495-503, 2006.

[20] A. R. Gilal, M. Omar, and K. I. Sharif, "DISCOVERING PERSONALITY TYPES AND DIVERSITY BASED ON SOFTWARE TEAM ROLES," in International Conference on Computing and Informatics, ICOCI 2013, 2013, pp. 259-264.

[21] J. S. Karn, S. Syed-Abdullah, A. J. Cowling, and M. Holcombe, "A study into the effects of personality type and methodology on cohesion in software engineering teams," Behav. Inf. Technol., vol. 26, no. 2, pp. 99-111, 2007.

[22] M. Omar, S.-L. Syed-Abdullah, and N. M. Hussin, "eTiPs: A Rule-based Team Performance Prediction Model Prototype," Procedia Technol., vol. 1, pp. 390-394, Jan. 2012.

[23] M. Omar, S.-L. Syed-Abdullah, and N. M. Hussin, "Developing a Team Performance Prediction Model: A Rough Sets Approach," in Informatics Engineering and Information Science, Springer, 2011, pp. 691-705.

[24] M. Omar, S.-L. Syed-Abdullah, and N. M. Hussin, "Analyzing personality types to predict team performance," in International Conference on Science and Social Research (CSSR 2010), 2010, pp. 624-628.

[25] E. M. Trauth, "Theorizing gender and information technology research," Encycl. Gend. Inf. Technol., vol. 2, pp. 1154-1159, 2006.

[26] J. Wajcman, Feminism confronts technology. Penn State Press, 1991.

[27] A. Qazi, R. G. Raj, M. Tahir, M. Waheed, S. U. R. Khan, A. Abraham, “A Preliminary Investigation of User Perception and Behavioral Intention for Different Review Types: Customers and Designers Perspective,” The Scientific World Journal, vol. 2014, Article ID 872929, 8 pages, 2014. doi:10.1155/2014/872929.

[28] L. F. Capretz, "Personality types in software engineering," Int. J. Hum. Comput. Stud., vol. 58, no. 2, pp. 207-214, 2003.

[29] L. F. Capretz, "Psychological Types of Brazilian Software Engineering Students," J. Psychol. Type, no. 5, pp. 37-42, 2008..

[30] L. G. Martínez, G. Licea, A. Rodríguez-Díaz, and J. R. Castro, "Experiences in Software Engineering Courses Using Psychometrics with RAMSET," in Proceedings of the Fifteenth Annual Conference on Innovation and Technology in Computer Science Education, 2010, pp. 244-248.

[31] K. C. Low, "Leadership thoughts to build your life on--Leading, the Jesus way," Leadersh. Organ. Manag. J., no. 4, pp. 1-12, 2008.

[32] P. T. Costa Jr and R. R. McCrae, "Personality stability and its implications for clinical psychology," Clin. Psychol. Rev., vol. 6, no. 5, pp. 407-423, 1986.

[33] J. T. M. TKalcic, M. Kunaver, J. Tasic, and A. Košir, "Personality based user similarity measure for a collaborative recommender system," Proc. 5th Work. Emot. Human-Computer Interact. world challenges, pp. 30-37, 2009. 
[34] C. J. Boyce, A. M. Wood, and N. Powdthavee, "Is personality fixed? Personality changes as much as 'variable' economic factors and more strongly predicts changes to life satisfaction," Soc. Indic. Res., vol. 111, no. 1, pp. 287-305, 2013.

[35] A. R. Gilal, J. Jaafar, M. Omar, S. Basri, and A. Waqas, "A Rule-Based Model for Software Development Team Composition: Team Leader Role with Personality Types and Gender Classification," Inf. Softw. Technol., vol. 74, pp. 105-113, 2016. 